\title{
O movimento formativo do pacto nacional pela alfabetização na idade certa: repercussões à alfabetização matemática
}

The formative movement of the national pact for literacy at the right age: impacts on math literacy El movimiento formativo del pacto nacional por la alfabetización en la edad adecuada: repercusiones a la alfabetización matemática

MARIA IOLANDA FONTANA

https://orcid.org/0000-0003-2688-9875

Universidade Tuiuti do Paraná

Programa de Pós-Graduação em Educação

Departamento de Educação

Curitiba, PR, Brasil

ETTIÈNE GUÉRIOS

http://orcid.org/0000-0001-5451-9957

Universidade Federal do Paraná

Programa de Pós-Graduação em Educação

Departamento de Educação

Curitiba, PR, Brasil

VANDA MARIA DE SOUZA

https://orcid.org/0000-0002-7237-0620

Universidade Tuiuti do Paraná

Programa de Pós-Graduação em Educação

Departamento de Educação

Curitiba, PR, Brasil

\begin{abstract}
Resumo: $\mathrm{O}$ artigo analisa o movimento formativo do PNAIC Matemática e suas repercussões à prática pedagógica de professores alfabetizadores. Discute dados qualitativos de entrevistas com professoras de escolas municipais de Curitiba e da revisão de literatura. A contribuição do programa é constatada, principalmente, pelo pacto entre entes federados e universidades públicas, a reflexão, o compartilhamento de experiências e a construção de saberes na perspectiva da alfabetização matemática. Aponta-se como contradição a descontinuidade da formação continuada de caráter nacional com políticas de governo.
\end{abstract}

Palavras-chave: Políticas de formação continuada de professores. PNAIC Matemática. Alfabetização matemática. 
Abstract: This article analyzes the formative movement of the National Pact for Literacy at the Right Age (PNAIC) and its impacts on the teaching practices of literacy teachers. It discusses qualitative data generated from interviews with teachers from municipal schools in Curitiba, and from the literature review. The contribution of the program is demonstrated, in particular by the pact between federal institutions and public universities, the reflection, the sharing of experiences, and the construction of knowledge from a mathematics literacy perspective. The study also points out as a contradiction the discontinuity of continuing education in the national policies.

Keywords: Policies for Teacher Continuing Education. PNAIC. Mathematics. Mathematical Literacy.

Resumen: El articulo analiza el movimiento formativo del PNAIC - Matemática y las repercusiones para la práctica pedagógica de los alfabetizadores. Analiza datos cualitativos de entrevistas con profesores de escuelas municipales de Curitiba y de la revisión de la literatura. La contribución del programa a la política de educación continua se evidencia, principalmente, en el intercambio de experiencias entre docentes en la perspectiva de la competencia matemática. La discontinuidady disociación entre los programas de formación, las políticas del gobierno, las secretarias de educación para la formación y la labor docente es contradictoria.

Palabras clave: Formación continua del profesorado. PNAIC-Matemáticas. Educación matemática.

\section{INTRODUÇÃO}

A ampla discussão na literatura educacional sobre a formação continuada de professores tem desencadeado políticas e programas institucionais que demandam pesquisas para sua análise e avaliação. Apesar do grande número de experiências de formação continuada existentes no Brasil, em acordo com Moriconi et al (2017) e Gatti (2019), são raros os estudos avaliativos que revelam evidências da eficácia da formação continuada de professores para a melhoria de suas práticas ou do desempenho de seus alunos. A revisão sistemática de Xavier e Bartholo (2019) sobre o Pacto Nacional pela Alfabetização na Idade Certa (PNAIC), período 2013 a 2017, ressalta limitações nos estudos encontrados sobre o programa na prática dos professores e na alfabetização das crianças, a maior parte deles apresenta a percepção de atores (em geral professores) sobre a implementação ou impacto do programa.

Nesse sentido, justifica-se a importância de investigar o PNAIC e contribuir com estudos sobre as repercussões do programa na formação e prática pedagógica de professores. Neste artigo, discute-se especificamente o PNAIC Matemática, oferecido no ano de 2014 aos professores alfabetizadores do Brasil.

O programa foi instituído pela portaria $n^{\circ} 867$, em 4 de julho de 2012 (BRASIL, 2012), com o objetivo de garantir a alfabetização até o $3^{\circ}$ ano do ciclo de alfabetização, construir propostas para a definição dos direitos de 
aprendizagem e desenvolvimento das crianças, reduzir a distorção entre idade e série na educação básica, melhorar o índice de desenvolvimento da educação básica (Ideb) e contribuir para o aperfeiçoamento da formação dos professores alfabetizadores.

As ações do PNAIC, em sua concepção inicial, diferenciam-se do formato tradicional de formação continuada, no que diz respeito à estrutura e conteúdo. Destacam-se como diferenciais a gestão compartilhada do programa entre a União, estados, Distrito Federal e municípios, a articulação entre universidades e secretarias de educação para realização do processo formativo de professores alfabetizadores e seus orientadores, concessão de bolsa auxílio aos professores, orientadores de estudos, coordenadores e formadores, a duração e continuidade do curso, distribuição de materiais didáticos, obras literárias, jogos e tecnologias educacionais.

Entidades de educadores e pesquisadores brasileiros ${ }^{1}$ têm manifestado a importância de políticas com investimentos na formação inicial e continuada de professores, articuladas com a melhoria das condições de trabalho nas escolas, no que diz respeito à relação entre o número de crianças, docentes e pedagogos, à efetividade da gestão democrática na escola, à jornada de trabalho, horas para estudo e preparação das aulas. Sem medidas correlacionadas entre programas de formação continuada e políticas educacionais mais amplas, o investimento feito pode se mostrar ineficaz.

A versão do PNAIC, objeto deste artigo, está regulamentada pela portaria $\mathrm{n}^{\circ}$ 826, de 7 de julho de 2017, que dispõe sobre suas ações, diretrizes gerais e a ação de formação no âmbito do Programa Novo Mais Educação (PNME) ${ }^{2}$. As ações do PNAIC e do PNME, em relação à portaria anterior, do ano de 2012, ampliaram a formação continuada para coordenadores pedagógicos e professores da educação infantil (BRASIL, 2017). Essa versão foi definida no contexto da aprovação da emenda constitucional no 95 (EC 95), de 15 de dezembro de 2016 (BRASIL, 2016), que instituiu um Novo Regime Fiscal (NRF) no país, abateu financiamentos nas áreas sociais, como educação e saúde. Como consequência, houve restrição de investimentos no programa, a participação dos professores tornou-se facultativa, o tempo da formação diminuiu para sete meses, as bolsas

1 Manifesto publicado no Portal da Anped, em 20/10/2017, com participação das entidades ABdC, ABRAPEC ANFOPE, ANPAE, ANPEd, CEDES. Disponível em: http://www.anped.org.br/news/ manifestacao-das-entidades-educacionais-sobre-politica-deformacao-de-professores-anunciada. Acesso em: 10 maio 2018.

2 O PNME, criado pela portaria MEC $n^{\circ}$ 1.144/2016, e regido pela resolução FNDE $n^{\circ}$ 5/2016, é uma estratégia do MEC, que tem como objetivo melhorar a aprendizagem em língua portuguesa e matemática no ensino fundamental, por meio da ampliação da jornada escolar de crianças e adolescentes. Disponível em: http://portal.mec.gov.br/programa-mais-educacao. Acesso em: 20 out. 2019.

1034 - Rev. Bras. Polít. Adm. Educ. - v. 37, n. 2, p. 1032 - 1052, mai./ago. 2021 
destinadas aos alfabetizadores foram suspensas e o valor da bolsa destinada aos demais atores do programa foi reduzida. Assim, a partir do ano de 2017, ocorreu o abrandamento da proposta de integração entre secretarias de educação e universidades, pois além de tornar facultativa a adesão ao PNAIC, reduziram-se os investimentos em materiais e bolsas aos participantes, elementos que favoreciam a execução da proposta e incentivavam a participação dos docentes e formadores, sendo o programa interrompido em 2018.

Segundo o Documento Orientador do MEC (BRASIL, 2017a), a principal diferença no programa em 2017 diz respeito a um maior direcionamento na intencionalidade pedagógica das formações e na atuação dos formadores, a partir da adoção de um modelo que pressupõe o fortalecimento da capacidade institucional local. Isso significa que o MEC delegou a adesão e o provimento de estrutura às secretarias de educação municipais e estaduais que, no entanto, em sua maioria, apresentam limitações de recursos e de profissionais para implementar a formação continuada de seus professores.

Nesse contexto, este artigo tem o objetivo de analisar o movimento formativo do Pacto Nacional pela Alfabetização na Idade Certa (PNAIC) Matemática e as repercussões para a prática pedagógica de professores alfabetizadores.

A pesquisa é de abordagem qualitativa e utilizou como procedimentos: levantamento documental, revisão sistemática integrativa de literatura (RSIL) e pesquisa de campo (CRESWELL, 2010). O levantamento documental teve o objetivo de discutir o PNAIC Matemática no contexto das políticas de formação continuada de professores do ciclo de alfabetização, destacando o papel do estado na definição de políticas educacionais. A RSIL teve o objetivo de destacar análises convergentes, divergentes, questionamentos e proposições com corpus constituído por 37 teses e dissertações, produzidas no período entre 2016 e 2018, obtidas por meio do descritor "PNAIC", com refinamento PNAIC Matemática. A pesquisa de campo teve o objetivo de dar significado à realidade que envolve o presente objeto de estudo e foi realizada no ano de 2017, por meio de entrevista semiestruturada com oito professoras do ciclo de alfabetização de quatro escolas da rede municipal de ensino (RME) de Curitiba que participaram do. PNAIC Matemática, selecionadas em função do maior e do menor desempenho no Ideb. A partir de compatibilização dos dados, discutem-se as repercussões para a prática pedagógica, as contradições e os avanços do programa como uma política nacional de formação continuada. 


\section{O PNAIC NO CONTEXTO DAS POLÍTICAS DE FORMAÇÃO CONTINUADA PARA A ALFABETIZAÇÃO MATEMÁTICA}

O PNAIC teve como referência o Pró-Letramento, ${ }^{3}$ criado pelo MEC no ano de 2005 e pela constituição em 2004 da Rede Nacional de Formação de Profissionais da Educação (Renafor), que reuniu centros de referência em formação de professores, favorecendo o diálogo entre e com IES.

O PNAIC Matemática apresentou avanços no âmbito dos materiais didáticos, literatura de apoio pedagógico, jogos e tecnologias educacionais; no tratamento dos conteúdos e conceitos matemáticos; na elaboração de avaliações sistemáticas; pela perspectiva lúdica, no modo de se relacionar com alunos e o ensino da Matemática em sala de aula e pelo desenvolvimento da atitude reflexiva e investigativa dos docentes.

Valoriza-se, entre os princípios do PNAIC para a proposta de formação de professores, o desenvolvimento de uma atitude de investigação e de constante questionamento, o que contribui para o professor pensar sobre os significados da alfabetização matemática e sobre como materializar os objetivos de seu ensino no ciclo de alfabetização. Essa proposta coincide com a defesa de educadores, como André (2001), Zeichner (2003), Zeichner e Diniz-Pereira (2005), entre outros, que entendem a importância da pesquisa no processo de formação docente para possibilitar, pela relação teoria e prática, resolver problemas advindos da prática pedagógica.

Para a orientação e reflexão sobre a alfabetização na perspectiva do letramento, o MEC organizou e distribuiu a todos os participantes do PNAIC oito cadernos que tratam da Matemática: Organização do Trabalho Pedagógico; Quantificação, Registros e Agrupamentos; Construção do Sistema de Numeração Decimal; Operações na Resolução de Problemas; Geometria; Grandezas e Medidas; Educação Estatística; Saberes Matemáticos e Outros Campos do Saber.

A alfabetização matemática refere-se à compreensão, à interpretação e à comunicação dos conteúdos matemáticos, tidos como iniciais para a construção do conhecimento matemático, ou seja, as primeiras noções de lógica, de aritmética e de geometria. No material de formação do PNAIC Matemática é utilizada a expressão "alfabetização matemática" e "alfabetização matemática na perspectiva do letramento". Nesse documento, Fonseca (BRASIL, 2014, p. 31) esclarece que a dimensão matemática da alfabetização na perspectiva do letramento, significa " $\mathrm{O}$

\footnotetext{
3 O programa Pró-Letramento Matemática, ação integrada ao Programa de Ações Articuladas (PAR), do governo federal, tem como meta a melhoria da qualidade de ensino. Foi direcionado a todos os professores que estavam em exercício, nos anos iniciais $\left(1^{\circ}\right.$ ao $5^{\circ}$ ano) do ensino fundamental das escolas públicas, com o objetivo de dar suporte aos docentes nas áreas de língua portuguesa (alfabetização/linguagem) e matemática.
} 
conjunto das contribuições da Educação Matemática no Ciclo de Alfabetização para a promoção da apropriação pelos aprendizes de práticas sociais de leitura e escrita de diversos tipos de textos, práticas de leitura e escrita do mundo."

Entende-se que o PNAIC, no seu formato inicial, contemplou, conforme a literatura analisada por Moriconi et al (2017, p. 11) $)^{4}$ os atributos comuns das iniciativas eficazes de formação continuada: foco no conhecimento pedagógico do conteúdo; métodos ativos de aprendizagem; participação coletiva; duração prolongada; coerência com as políticas e demandas da escola, docentes e de pesquisadores.

No entanto, um fator importante a ser considerado no contexto das políticas públicas é o modo como as propostas de formação continuada são concebidas e desenvolvidas para colaborar com o desenvolvimento profissional docente. Segundo Diniz-Pereira (2019), para discutir a formação continuada de professores, é necessário considerar a ideia do desenvolvimento profissional destes profissionais como uma concepção de formação não dissociada da própria realização do trabalho docente. Portanto, é necessário discutir o princípio da indissociabilidade entre a formação e as condições adequadas para a realização do trabalho docente.

D’Ambrósio (2016) chama atenção para a postura dos professores frente às possibilidades de melhoria da prática pedagógica. Entende-se que, sem o exercício da crítica em processos formativos, não há possibilidade de transformação das condições de trabalho, conforme afirma:

Particularmente, deve-se oferecer, na formação de professores, espaço para suas reflexões sobre o porquê e o como das condições de trabalho na educação do mundo atual, no cotidiano escolar. Se os futuros professores e professoras de uma instituição não se ativarem em reflexões mais ousadas de crítica ao sistema vigente, ficando à espera de decisões emanadas do poder central, nada mudará. (p. 4).

Acredita-se que "Políticas públicas para a formação de professores não podem ser temporais e circunstanciais, e seus programas constitutivos precisam ter respeitados seus tempos para que, analisados e aperfeiçoados, ofereçam oportunidades de melhoria qualitativa da educação brasileira" (GUÉRIOS; RIBEIRO; FOLLADOR, 2017, p. 75). De fato,

4 A pesquisa de Moriconi et al (2017) baseia-se em revisões de estudos empíricos, que avaliaram a eficácia de programas de formação continuada de professores, realizados na Austrália, Canadá, Reino Unido, Holanda, Nova Zelândia, Israel e, em sua maioria, nos Estados Unidos; também foram agregados a esses textos outras revisões, compilações e apanhados sobre experiências, modelos e abordagens de formação continuada de diversas origens; dentre eles, trabalhos produzidos no contexto da América Latina. 
Qualquer política de formação de professores precisa de tempo para consolidar práticas e aprofundar conhecimentos. [...] Qualquer interrupção na rede de trabalho que se formou pode colocar em risco o potencial transformador do PNAIC, que se estabeleceu como uma experiência bem-sucedida de regime de colaboração entre os entes federados e as universidades públicas. (ANPAE, 2015, s/p.).

Investigar a produção do conhecimento de pesquisadores brasileiros expressos em teses e dissertações sobre o PNAIC Matemática pode revelar importantes constatações sobre as contradições e os avanços deste programa como uma política de formação continuada e as repercussões para a prática pedagógica.

\section{O PNAIC MATEMÁTICA EM TESES E DISSERTAÇÕES NO PERÍODO 2016 A 2018}

Os resultados obtidos na pesquisa do Catálogo de Teses e Dissertações da Capes se mostraram significativos, considerando as constatações de pesquisadores brasileiros sobre o programa em diferentes contextos, sistemas de ensino e secretarias de educação. Com a utilização do descritor "PNAIC" foram encontrados 331 trabalhos realizados entre 2014 e 2018. Destes, 37 foram realizados de 2016 a 2018 e tratam especificamente do PNAIC Matemática. Nos anos de 2014 e 2015 não foram encontrados trabalhos. No ano de 2016, foram encontradas 10 dissertações e 1 tese; no ano de 2017, 13 dissertações; e no ano de 2018, 13 dissertações. A maioria das pesquisas, ou seja, 60\% foram realizadas em Programas de Pós-Graduação em Ensino em Ciências e Matemática e 35\% em Programas de Pós-Graduação em Educação. A Universidade Federal do Paraná (UFPR) foi a instituição que mais pesquisou a temática.

Conforme explicitado nos resumos dos trabalhos analisados, todas as pesquisas foram de abordagem qualitativa e utilizaram diferentes tipologias e procedimentos, tais como: pesquisa bibliográfica e documental, estudo de caso, história oral, análise de narrativas, análise de conteúdo e análise de discurso.

A sistematização da empiria obtida, conforme Quadro 1, resultou em três eixos temáticos: 1) "O PNAIC como política de formação continuada de professores", investigado em uma tese e 16 dissertações; 2) "Alfabetização matemática no PNAIC", investigado em 10 dissertações; 3) "O PNAIC e as repercussões na prática pedagógica”, investigado em 10 dissertações. Os trabalhos analisam o PNAIC em sistemas públicos de ensino de diferentes estados e cidades do Brasil. 


\section{Quadro 1 - Eixos temáticos: dissertação/tese}

\begin{tabular}{|c|c|c|c|c|c|c|c|}
\hline \multirow{3}{*}{$\begin{array}{c}\text { A/ } \\
\text { quantidade }\end{array}$} & \multicolumn{7}{|c|}{ Eixos temáticos } \\
\hline & \multicolumn{3}{|c|}{$\begin{array}{l}\text { PNAIC como política de formação continuada } \\
\text { de professores }\end{array}$} & \multicolumn{2}{|c|}{$\begin{array}{l}\text { PNAIC e a formação para a } \\
\text { alfabetização matemática }\end{array}$} & \multicolumn{2}{|c|}{$\begin{array}{l}\text { PNAIC e as repercussões } \\
\text { na prática pedagógica }\end{array}$} \\
\hline & 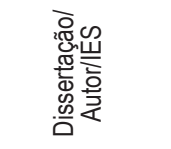 & 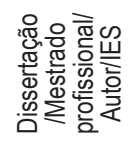 & 出 & 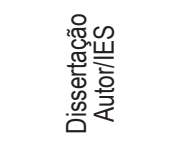 & 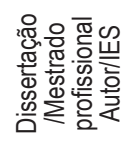 & 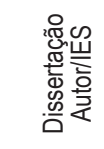 & 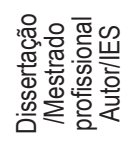 \\
\hline 2016 & $\begin{array}{l}\text { Souza/UFRJ } \\
\text { Mindiatel } \\
\text { UFPR }\end{array}$ & & $\begin{array}{l}\text { Montezumal } \\
\text { UFSCAR }\end{array}$ & $\begin{array}{l}\text { Francischetti/ } \\
\text { UFSCAR } \\
\text { Giombelli/ } \\
\text { UFFS/SC } \\
\text { Pereiral } \\
\text { UFU }\end{array}$ & $\begin{array}{l}\text { Pereira/ } \\
\text { UNESPI } \\
\text { Bauru }\end{array}$ & $\begin{array}{l}\text { Costa/ } \\
\text { UFPR } \\
\text { Elias/ } \\
\text { ULBRA }\end{array}$ & $\begin{array}{l}\text { Silval } \\
\text { UFPR } \\
\text { Ferreira/ } \\
\text { UFPEL }\end{array}$ \\
\hline 2017 & $\begin{array}{l}\text { Piasson/ } \\
\text { UNEMAT } \\
\text { Santos/ } \\
\text { UNEMAT } \\
\text { Silval } \\
\text { UNEMAT } \\
\text { Paula/ } \\
\text { UNIMAT } \\
\text { Santos/UNB }\end{array}$ & $\begin{array}{l}\text { Santos/ } \\
\text { UFLA } \\
\text { Borges/ } \\
\text { IFG }\end{array}$ & & $\begin{array}{l}\text { Andrade/ } \\
\text { UFPR } \\
\text { Passos/ } \\
\text { UFPR } \\
\text { Pudelcol } \\
\text { UFPR }\end{array}$ & $\begin{array}{l}\text { Correal } \\
\text { IFES }\end{array}$ & $\begin{array}{l}\text { Maciel/ } \\
\text { UFFS } \\
\text { Callejas/ } \\
\text { UFMT }\end{array}$ & \\
\hline 2018 & $\begin{array}{l}\text { Barros/UFPE } \\
\text { Lopes/UFPI } \\
\text { Sousa/UTP } \\
\text { Toja/UFSM } \\
\text { Souzal } \\
\text { UNEMAT/BBG } \\
\text { Koga/UFABC }\end{array}$ & $\begin{array}{l}\text { Assis/ } \\
\text { UEPB }\end{array}$ & & $\begin{array}{l}\text { Souzal } \\
\text { UESB/ } \\
\text { JEQUIÉ } \\
\text { Siqueiral } \\
\text { FEUSP }\end{array}$ & & $\begin{array}{l}\text { Weberl } \\
\text { UFSC } \\
\text { Pugas/ } \\
\text { UFT }\end{array}$ & $\begin{array}{l}\text { Carvalho/ } \\
\text { UFMG } \\
\text { Bravin/ } \\
\text { FVC }\end{array}$ \\
\hline Total & \multicolumn{3}{|c|}{17} & \multicolumn{2}{|c|}{10} & \multicolumn{2}{|c|}{10} \\
\hline
\end{tabular}

Fonte: Catálogo de teses e dissertações da Capes $^{5}$. Organização: as autoras.

A leitura dos resumos e de considerações finais dos 37 trabalhos encontrados trouxeram elementos para a elaboração de uma síntese integrativa dos resultados apontados pelos pesquisadores. Apresentam-se constatações de alguns autores com o objetivo de destacar análises convergentes, divergentes, questionamentos e proposições. Para a seleção dos textos foram usados critérios qualitativos, considerando sua pertinência em relação aos objetivos deste trabalho, sendo: a) Artigos que apresentaram a abordagem crítica de políticas de formação continuada de professores e da prática pedagógica de alfabetização matemática; b) Descrição dos resultados de trabalhos selecionados proporcionalmente $(20 \%)^{6}$ os

5 Pesquisa no Catálogo das teses e dissertações. Disponível em: https://catalogodeteses.capes.gov.br/ catalogo-teses/\#!/. Acesso em: 12 out. 2019.

6 O Princípio de Pareto, também conhecido como "Regra 80/20", estabelece que, comumente, aproximadamente $80 \%$ dos efeitos vêm de $20 \%$ das causas. 
3 eixos: PNAIC como política de formação continuada de professores (4), PNAIC e a formação para a alfabetização matemática (2) e PNAIC e as repercussões na prática pedagógica (2).

As pesquisas relacionadas ao eixo temático "PNAIC como política de formação continuada de professores" apontaram repercussões do programa sob diferentes perspectivas, que possibilitaram a compreensão crítica da proposta para seu aperfeiçoamento, conforme resultados revelados nos trabalhos de Souza (2016), Montezuma (2016), Mindiate (2016) e Lopes (2018).

Souza (2016) constatou a falta de conhecimentos específicos em Matemática das professoras alfabetizadoras e apesar dessas dificuldades o PNAIC proporcionou a criação de práticas pedagógicas que estimularam os alunos a construir os conceitos matemáticos.

Montezuma (2016) revelou indicativos de desenvolvimento profissional das professoras a partir dos programas de governo, como o PNAIC. No entanto, na prática de sala de aula, as professoras entram em conflito com as orientações teórico-metodológicas recebidas e assumem práticas que poderiam ser consideradas como insubordinação criativa, quando o professor cria para além do conhecimento recebido em cursos e faz escolhas pedagógicas para promover aprendizagens. Os dados revelaram também o desconforto das professoras frente à precarização profissional sentida no trabalho docente.

Mindiate (2016) ressaltou, a partir de narrativas de pesquisadores que participaram da formulação do PNAIC, a necessidade de compreendê-lo de modo crítico para colaborar com novas formulações políticas para formação continuada na perspectiva do letramento.

Lopes (2018) constata que a formação no PNAIC possibilitou reflexões sobre o desenvolvimento da prática cotidiana, consolidação e reconstrução de saberes e se constituiu em um lugar de aprendizagem e troca de experiências a partir da mobilização dos saberes dos professores utilizados no cotidiano da prática docente.

As pesquisas do eixo temático "PNAIC e a formação para a alfabetização matemática" revelaram as seguintes contribuições: reconhecimento das professoras alfabetizadoras em relação aos conteúdos da alfabetização matemática na perspectiva do letramento e o reconhecimento da importância do desenvolvimento do pensamento geométrico (FRANCISCHETTT, 2016; SIQUEIRA, 2018); valorização da perspectiva metodológica da resolução de problemas e da ludicidade (PUDELCO, 2017); os materiais do PNAIC contribuíram para a formação de professores alfabetizadores na perspectiva do letramento (SIQUEIRA, 2018; SOUZA, 2018). 
Foram apontados como problemas: o tempo para aprendizagem dos conteúdos e a falta de formação dos orientadores na área de Matemática, como também, o distanciamento da história da Matemática e das tecnologias da informação e comunicação (PEREIRA, 2016); a não compreensão dos conceitos relativos às estruturas aditivas (GIOMBELLI, 2016; PEREIRA, 2016), a necessidade de valorização dos conteúdos clássicos da geometria, via análise lógico-histórica (PEREIRA, 2016), poucos problemas envolveram combinatória, e houve ausência de problemas de transformação com estado inicial desconhecido (PUDELCO, 2017). A seguir são abordados os trabalhos de Francischetti (2016) e de Pereira (2016a) pela oposição das considerações de um e de outro, o que permite leitura reflexiva sobre o movimento formativo do PNAIC Matemática e suas repercussões à prática pedagógica de professores alfabetizadores.

Francischetti (2016) ressalta a contribuiçãodo PNAIC para o conhecimento teórico das professoras referente a conceitos próprios da alfabetização matemática na perspectiva do letramento. A formação colaborou para a conscientização das professoras acerca do desenvolvimento do pensamento no ciclo de alfabetização e que o estudo teórico das propriedades dos elementos geométricos possibilitou a ressignificação de práticas pedagógicas e de saberes próprios da docência em Matemática, rompendo com a predominância dos aspectos figurais sobre os conceituais, o que amplia o desenvolvimento do pensamento geométrico. Em contraposição a práticas aplicacionistas e memorísticas vinculadas a situações fictícias, as formações ampliaram as práticas contextualizadas por meio de problematizações relacionadas ao cotidiano dos alunos.

Pereira (2016a) revelou que os alunos do ciclo de alfabetização não têm domínio dos conteúdos da geometria espacial esperados e que a formação do PNAIC não contribuiu para melhor desempenho de professores e alunos. Apontou para a necessidade de valorização dos conteúdos clássicos da geometria, via análise lógico-histórica. Considera que o conteúdo matemático componente do eixo Geometria, tal como proposto pelo PNAIC, promove o desenvolvimento do pensamento empírico em detrimento do pensamento teórico. $\mathrm{O}$ aligeiramento dado aos conteúdos da geometria espacial e as formas empírico-quantitativas da abordagem aos conteúdos impedem a formação qualitativa para a alfabetização matemática. Afirma que a formação teórica dos conteúdos matemáticos e a didático-pedagógica devem ser apropriadas e ultrapassar a dimensão pragmática, o que compromete a prática dos professores e a decorrente aprendizagem, no caso, da geometria espacial.

As pesquisas referentes ao eixo "PNAIC e as repercussões na prática pedagógica" destacaram contribuições, como: o desenvolvimento da postura reflexiva dos profissionais que cursaram o PNAIC (SILVA, 2016), a ressignificação 
de suas práticas, a organização de sequências didáticas, a compreensão de conceitos matemáticos e de atividades lúdicas para a alfabetização matemática (CALLEJAS, 2017; CARVALHO, 2018; COSTA, 2016; PUGAS, 2018; WEBER, 2018); о desenvolvimento de saberes disciplinares e curriculares dos professores quanto à resolução de problemas e à compreensão da avaliação da aprendizagem (PUGAS, 2018); o material didático do PNAIC provocou maior abertura para a exposição do raciocínio pelos alunos (CARVALHO, 2018; WEBER, 2018). Destacam-se as pesquisas de Carvalho (2018) e Weber (2018), que revelam contribuições do PNAIC para a prática pedagógica na perspectiva da alfabetização matemática e reconhecem a necessidade de compromissos entre escolas e entes federativos para melhor efetividade das políticas de formação e trabalho de professores alfabetizadores.

Carvalho (2018) ressaltou que o uso do material do PNAIC provocou mudanças na relação com os estudantes, principalmente em função de uma maior abertura para a exposição do raciocínio pelos alunos e de um trabalho lúdico com jogos. Apontou que o programa precisa considerar a complexidade social das condições de trabalho nas escolas e dialogar com outras políticas públicas, articular-se com um plano de carreira, de maneira a valorizar melhor o desenvolvimento profissional do professor.

Weber (2018) constatou que os professores valorizaram a possibilidade de reflexões e de socialização de práticas entre os colegas, a compreensão de conceitos matemáticos, ampliação de conhecimentos sobre práticas de ensino com a utilização de materiais manipuláveis e de atividades lúdicas e reflexões sobre o planejamento. Apontou como dificuldades o tempo insuficiente para planejar as atividades, a quantidade de alunos na turma, o acesso aos materiais. Problematizou que transformações nas práticas pedagógicas dependem das contribuições de um curso, mas também das relações entre secretarias de educação e o governo e o desejo pessoal de cada profissional.

Enfim, este estudo encontrou em 36 dissertações e 1 tese, contribuições, considerando a abordagem da política de formação continuada de professores alfabetizadores, aprendizagem dos conteúdos da alfabetização matemática na perspectiva do letramento e a ressignificação da prática pedagógica. Entre as problematizações, ressalta-se a indicação para o aperfeiçoamento e continuidade do PNAIC, tanto na dimensão de sua proposta pedagógica, como na articulação com políticas que invistam na melhoria das condições de trabalho nas escolas e dialogar com outras políticas públicas, de maneira a valorizar o desenvolvimento profissional do professor. Entende-se que sem essa correlação, o desenvolvimento profissional docente não se materializa, dificultando práticas pedagógicas na perspectiva da alfabetização matemática. 


\section{REPERCUSSÕES DO PNAIC MATEMÁTICA NA VISÃO DE PROFESSORAS DA REDE MUNICIPAL DE ENSINO DE CURITIBA}

Para dar significado à realidade que envolve o presente objeto de estudo, foi realizado, no ano de 2017 um trabalho de campo ${ }^{7}$ em quatro escolas públicas da RME de Curitiba. Aceitaram participar da pesquisa oito professoras que permaneciam atuando no ciclo de alfabetização desde a realização do curso do PNAIC Matemática no ano de 2014. O objetivo foi identificar repercussões do programa na formação do professor do ciclo de alfabetização, na perspectiva da alfabetização matemática. Em outras palavras, identificar se a formação em Matemática, conforme as ações do PNAIC, foi compreendida e praticada pelo professor alfabetizador.

As entrevistas foram realizadas com as oito professoras alfabetizadoras, por meio de um roteiro semiestruturado. Os dados foram organizados em duas categorias de análise: formação continuada e prática pedagógica.

Com relação à categoria "formação continuada", constatou-se que seis professoras, identificadas como P1, P2, P3, P5, P7, P8, possuem entre 7 e 23 anos de experiência no magistério, apenas duas professoras possuem menos de cinco anos de experiência (P4, P6). Todas têm formação em nível superior, sendo cinco formadas em Pedagogia (P1, P2, P3, P5, P6), uma formada em curso normal superior (P8), uma licenciada em Matemática (P4), uma é fonoaudióloga com especialização em Alfabetização (P7). As professoras ressaltaram que a Secretaria Municipal de Educação de Curitiba (SME) promove vários cursos de formação continuada, a maioria práticos, com o objetivo de aplicação em sala de aula, sendo o PNAIC, para a maioria das professoras, o curso mais valorizado.

Todas as professoras reconheceram as contribuições do PNAIC, embora tenham destacado aspectos diferentes, como: reflexão sobre a prática pedagógica e troca de experiências, enriquecimento para a utilização de materiais concretos (P2); benefício do recurso lúdico aliado à alfabetização matemática (P1, P2); ressignificação da prática por meio de atividades significativas, como jogos e material concreto (P1, P3, P5, P6, P7); valorização da sequência didática (P4); gosto dos alunos pela alfabetização matemática, demonstração pelas professoras que não é tão difícil aprender Matemática (P3); ampliação da capacidade criativa para aplicação de recursos em sala de aula (P6); desenvolvimento do raciocínio por meio de jogos (P7).

\footnotetext{
7 A pesquisa de campo foi autorizada pela Secretaria Municipal de Educação de Curitiba e aprovada no Comitê de Ética da instituição universitária, à qual a pesquisa de mestrado estava vinculada, pelo parecer $\mathrm{n}^{\mathrm{o}}$ 2.614.791.
} 
O PNAIC Matemática foi considerado por todas as professoras como um curso que trouxe muita contribuição prática, mas, em alguns casos, alheio à teoria matemática:

Gostei bastante, porque eu não tinha nenhum conhecimento de alfabetização matemática. Eu tive uma professora do PNAIC que foi ótima, excelente, trouxe bastante prática de sala de aula, deixou a teoria, e praticamos bastante para a sala de aula. (P6, 2017).

As narrativas das professoras coincidiram com os achados de Silva (2016) e Costa (2016), que também investigaram professores da RME de Curitiba e com os resultados de Carvalho (2018) com professores da RME de Contagem-MG. Esses pesquisadores também constataram repercussões teóricas e práticas do PNAIC na formação relacionada à alfabetização matemática, e identificaram, a partir da possibilidade de reflexão e uso de material disponibilizado no curso, mudanças na relação com seus estudantes, principalmente em função de um trabalho mais lúdico, a partir de jogos.

Sobre a formação do PNAIC, a maioria das professoras entrevistadas indicam como problemas: a dificuldade em participar do curso devido ao horário; a quantidade de estudo; a não continuidade dos professores que cursaram o PNAIC no ciclo de alfabetização; a falta de domínio dos conteúdos do curso por parte de alguns dos professores orientadores de estudos; ao curto tempo do curso; a necessidade de continuidade. Destacam-se as seguintes respostas:

Achei muito errado que algumas professoras, que fizeram o PNAIC de Matemática, agora não estão em sala como regente de classe do ciclo de alfabetização, mas dando aula de ciências. (P3, 2017).

O PNAIC poderia ser feito com mais tempo ou, sei lá, de forma menos cansativa. Trabalhar a semana inteira e estudar sábado o dia todo não é fácil. O curso é muito bom, mas tem muita coisa para estudar, e aí acaba sendo puxado. (P5, 2017).

A pesquisa de Silva (2016), com professores da RME de Curitiba, também ressaltou o problema da curta duração do curso e a dificuldade de compreensão dos conteúdos, tanto dos professores como de alguns orientadores de estudos que não possuíam formação na área de Matemática.

Outro problema apontado foi a dificuldade em realizar avaliação coerente com a heterogeneidade de aprendizagem das crianças, conforme orientação recebida no PNAIC. As professoras demonstraram a compreensão de que a avaliação deve ser contínua e em vários momentos, por meio de diferentes instrumentos e, inclusive, em atividades lúdicas: 
Já sabemos, mais que nunca, que as salas são heterogêneas e que, por trás de cada um, há uma história de vida que não pode ser ignorada. (P1, 2017).

A abordagem sobre a avaliação no processo formativo do PNAIC não foi verificada no levantamento das teses e dissertações. Infere-se que esta discussão precisa ser ampliada na formação continuada de professores alfabetizadores. D’Ambrósio (2014, p. 57) chama atenção para o fato de que "os maiores entraves a uma melhoria da educação têm sido o alto índice de reprovação e a enorme evasão, ambos estão relacionados." O autor afirma, ainda, que o sistema de avaliação no Brasil está completamente equivocado e deve ser repensado.

A análise da categoria "prática pedagógica" considerou as falas das professoras sobre os conteúdos do PNAIC e as suas repercussões. As professoras ressaltaram a valorização dos jogos como recursos significativos para a alfabetização matemática:

Ressignificar a prática pedagógica fazendo uso de jogos como atividades significativas e prazerosas para os estudantes. (P5, 2017).

Gostei bastante, porque eu só tinha experiência com educação infantil, e o PNAIC me trouxe uma boa bagagem com relação a jogos, maneiras diferentes de trabalhar a Matemática. (P6, 2017).

Pode-se inferir que a valorização dos jogos e da ludicidade, na visão das professoras, repercutiu em experiências viabilizadas pelo acesso ao material concreto, disponibilizado no curso, que possibilitaram bons resultados no desenvolvimento do raciocínio e aprendizagem dos conceitos matemáticos.

Sobre os materiais oferecidos no PNAIC, as professoras destacaram o tapetinho para trabalhar a posição do número (P1, P3), os jogos (P2, P4, P5, P6, P8), a caixa Matemática e o Tangran (P3, P7):

Uma das metodologias que veio a enriquecer mais ainda foi o tapetinho, o material concreto; ali, a gente pode ver que realmente dá resultado, a questão do contar com os alunos, para eles aprenderem unidade, dezena e centena de milhar, eles iam amarrando. (P3, 2017).

Portanto, foi possível constatar que, para as oito professoras da RME de Curitiba, o PNAIC trouxe repercussões que contribuíram para ressignificar a prática pedagógica, coincidindo com os achados das dissertações e teses apresentadas na revisão de literatura. Tanto as professoras experientes como as menos experientes, as formadas em Pedagogia como a licenciada em Matemática, destacaram o conhecimento que adquiriram sobre as atividades lúdicas, especialmente o uso de jogos para a alfabetização matemática na perspectiva do 
letramento. Esse destaque demonstra a necessidade de processos de formação que possibilitem a reflexão sobre a teoria e a prática nas salas de aula. No caso do PNAIC, essa condição foi efetivada pelos materiais concretos disponibilizados aos professores e pelos relatos das experiências exitosas para aprendizagem nas classes de alfabetização.

Chamou a atenção que, na RISL, na proposta do PNAIC Matemática, a resolução de problemas é valorizada, no entanto, as professoras investigadas não destacaram sua relevância para a formação e prática pedagógica. $\mathrm{O}$ tema foi investigado apenas por Pudelco (2017), que ressaltou a proximidade da proposta do PNAIC com estudos nessa área e constou nos resultados das pesquisas de Pugas (2018) e Pereira (2016).

\section{CONSIDERAÇÕES FINAIS}

Conclui-se que o movimento formativo do PNAIC, no âmbito das universidades, secretarias de educação e escolas públicas, favoreceu o desenvolvimento de pesquisas e acompanhamento do programa, constatado na significativa produção do conhecimento sobre o tema. A abordagem qualitativa das pesquisas, realizadas com diferentes metodologias e em estados e municípios distintos, expressa um conjunto de dados relevantes para a avaliação e redirecionamento de políticas públicas e aperfeiçoamento de programas de formação continuada. Este estudo constatou convergências sobre o programa, considerando o conjunto dos 37 trabalhos analisados e os dados obtidos na pesquisa com as oito professoras da RME de Curitiba. Ressalta-se como importante repercussão deste programa a reflexão sobre a organização do trabalho pedagógico e o estudo de conteúdos da alfabetização matemática.

As evidências sobre a valorização dos jogos e atividades lúdicas indicam que a formação contribuiu para os professores estabelecerem a tão necessária relação teoria e prática, efetivada por meio da realização de experiências em sala de aula, com o manuseio dos materiais disponibilizados pelo programa, sistematizarem conhecimentos e constatarem as contribuições para aprendizagem da criança do ciclo de alfabetização. Portanto, não obstante alguns problemas apontados referentes à estrutura e organização do programa, constata-se que a formação trouxe contribuições para a ampliação de saberes e ressignificação da prática dos professores, assim como sugerem as pesquisas em educação matemática.

Com relação à continuidade e ao acompanhamento do PNAIC, destacase a necessidade de avançar a formação na perspectiva do desenvolvimento profissional, que favoreça a fundamentação teórica, a troca de saberes 
experienciais, bem como a reflexão e investigação individual e coletiva sobre a prática pedagógica. Porém, a especificidade da realidade educacional brasileira e a condição docente no Brasil suscitam reivindicar, no movimento das políticas públicas educacionais, a garantia das condições adequadas para a realização do trabalho pedagógico competente e socialmente comprometido com o ensino emancipador.

Ressalta-se a necessidade de se garantir a continuidade de políticas públicas de formação continuada em larga escala, a exemplo do PNAIC, pois mesmo com as dificuldades de organização, estrutura e recursos gerados por motivo de sua abrangência nacional, somente assim será possível promover avanços no processo de alfabetização em todas as escolas públicas do Brasil. Entende-se que o PNAIC, por sua abrangência e importância, constatadas pelos pesquisadores brasileiros, precisa ser avaliado e aperfeiçoado, pois se aproxima das características de propostas consideradas eficazes e que podem promover melhoria qualitativa da alfabetização na idade certa.

Ainda que a qualificação docente influencie no aprendizado dos alunos, entende-se que há outros fatores também relevantes para boas práticas em sala de aula, como, por exemplo, os referentes às condições de trabalho. Significa ter tempo e espaço para realizar planejamento, organização de material de apoio para o ensino, elaboração de instrumentos de avaliação e análise dos resultados, assim como a gestão democrática na escola que integre família e professores no planejamento de uma ação educativa mais ampla.

\section{REFERÊNCIAS}

ANDRÉ, Marli Eliza Dalmazo Afonso de. O papel da pesquisa na formação e na prática dos professores. Campinas: Papirus, 2001.

ASSOCIAÇÃO NACIONAL DE POLÍTICA E ADMINISTRAÇÃO DA EDUCAÇÃO (ANPAE). Carta aberta em defesa do Pacto Nacional pela Alfabetização na Idade Certa. 2015. Disponível em: https://www.anpae.org. br/website/documentos/CartaAbertaemDefesadoPNAIC.pdf. Acesso em: 10 set. 2020.

BRASIL. Ministério da Educação. Portaria no 867, de 4 de julho de 2012. Institui o Pacto Nacional pela Alfabetização na Idade Certa. Diário Oficial da União, Brasília, DF, 5 jul. 2012. 
BRASIL. Ministério da Educação. Pacto Nacional pela Alfabetização na Idade Certa: caderno de apresentação - alfabetização matemática. MEC/SEB. Brasília, DF, 2014.

BRASIL. Casa Civil. Subchefia para Assuntos Jurídicos. Emenda Constitucional $\mathbf{n}^{\circ} \mathbf{9 5}$, de 15 de dezembro de 2016. Altera o Ato das Disposições Constitucionais Transitórias, para instituir o Novo Regime Fiscal, e dá outras providências. Brasília, DF, 2016. Disponível em: http://www.planalto.gov.br/ccivil_03/constituicao/ emendas/emc/emc95.htm Acesso em: 28 jul. 2020.

BRASIL. Ministério da Educação. Secretaria de Educação Básica. Pacto Nacional pela Alfabetização na Idade Certa: documento orientador [PNAIC em ação]. Brasília, DF, 2017a. Disponível em: http://pacto.mec.gov.br/images/pdf/doc_ orientador/doc_orientador_versao_final.pdf. Acesso em: 28 jul. 2020.

BRASIL. Ministério da Educação. Portaria no 826, de 7 de julho de 2017. Dispõe sobre o Pacto Nacional pela Alfabetização na Idade Certa - PNAIC, suas ações, diretrizes gerais e a ação de formação no âmbito do Programa Novo Mais Educação - PNME. Diário Oficial da União, Brasília, DF, seção 1, n. 130, p. 20, 10 jul. 2017b.

CARVALHO, Ana Cristina Goncalves. Percepções de professoras sobre as implicações da formação do PNAIC-Matemática em suas práticas. $148 \mathrm{f}$. Dissertação (Mestrado Profissional em Educação e Docência) - Universidade Federal de Minas Gerais, Belo Horizonte, 2018.

COSTA, Edicleia Xavier da. Narrativas de professores alfabetizadores sobre o PNAIC de Alfabetização Matemática. 259 f. Dissertação (Mestrado em Educação em Ciências e em Matemática) - Universidade Federal do Paraná, Curitiba, 2016.

CRESWELL, John W. Projetos de pesquisa: métodos qualitativos. Porto Alegre: Artmed, 2010.

D’AMBRÓSIO, Ubiratan. Educação matemática: da teoria à prática. 23. ed. Campinas: Papirus, 2014. 
D'AMBRÓSIO, Ubiratan. A Educação Matemática hoje: Por que e como? In: ENCONTRO NACIONAL DE EDUCAÇÃO MATEMÁTICA. Educação Matemática na Contemporaneidade: desafios e possibilidades, 12., 2016, São Paulo. Anais eletrônicos [...], São Paulo, 2016. Disponível em: http://www. sbembrasil.org.br/enem2016/anais/pdf/8490_4451_ID.pdf. Acesso em: 28 jul. 2020 .

DINIZ-PEREIRA, Júlio Emílio. Desenvolvimento profissional docente: um conceito em disputa. In: IMBERNÓN, Francisco; SHIGUNOV NETO, Alexandre; FORTUNATO, Ivan (org.). Formação permanente de professores: experiências iberoamericanas. São Paulo: Edições Hipótese, 2019.

FRANCISCHETTI, Elisângela Ap. A geometria no ciclo de alfabetização: outros olhares a partir do PNAIC 2014. 164 fls. Dissertação (Mestrado Educação) Universidade Federal de São Carlos, São Carlos, 2016.

GATTI, Bernardete A. et al. Professores do Brasil: novos cenários de formação. Brasília: UNESCO, 2019.

GIOMBELLI, Cirlei. Implicações da formação do PNAIC nas compreensões dos professores sobre as elaborações de conceitos matemáticos pelas crianças do ciclo de alfabetização. 2016. 183 f. Dissertação (Mestrado em Educação) - Universidade Federal da Fronteira Sul, Chapecó, 2016.

GUÉRIOS, Ettiène; RIBEIRO, Alessandro; FOLLADOR, Dolores. Políticas públicas e a formação de professores que ensinam matemática: perspectivas e diálogos entre Universidades e Educação Básica. In: BRANDT, Célia Fink; GUÉRIOS, Ettiène. Práticas e Pesquisas no campo da educação matemática. Curitiba: CRV, 2017. p. 59-78.

LOPES, Laurilene Cardoso da S. Formação continuada no âmbito do pacto nacional pela alfabetização na idade certa: contribuições para o ensino de Matemática e para a prática alfabetizadora. 128 fls. Dissertação (Mestrado em Educação) - Universidade Federal do Piauí, Teresina, 2018. 
MARTINS PEREIRA, Mariana Martins. Saberes metodológicos para o ensino de Matemática na perspectiva do Pacto Nacional pela Alfabetização na Idade Certa. 144 f. Dissertação (Mestrado em Educação) - Universidade Federal de Uberlândia, Uberlândia, 2016.

MINDIATE, Manuel Joaquim. Uma compreensão da alfabetização matemática como política pública no Pacto Nacional pela Alfabetização na Idade Certa. 87 f. Dissertação (Mestrado em Educação em Ciências e em Matemática) - Universidade Federal do Paraná, Curitiba, 2016.

MONTEZUMA, Luci Fatima. Entre fios e teias de formação: narrativas de professoras que trabalham com Matemática nos anos iniciais - constituição da docência e os desafios da profissão na educação pública estadual paulista frente aos programas de governo no período de 2012 a 2015. 327 f. Tese (Doutorado em Educação) - Universidade Federal de São Carlos, São Carlos, 2016.

MORICONI, Gabriela Miranda (coord.) et al. Formação continuada de professores: contribuições da literatura baseada em evidências, São Paulo: FCC, 2017.

PEREIRA, Adauto de Jesus. Contribuições da pedagogia histórico-crítica para o ensino da geometria espacial no ciclo de alfabetização. 2016. 104 f. Dissertação (Mestrado Profissional em Docência para a Educação Básica) Universidade Estadual Júlio de Mesquita, Bauru, 2016.

PUDELCO, Milena S. Resolução de problemas: saberes de professores participantes de políticas públicas de formação continuada em Matemática. 241 f. Dissertação (Mestrado em Educação em Ciências e em Matemática) Universidade Federal do Paraná, Curitiba, 2017.

PUGAS, Seila Alves. Entre números e letras considerações de professoras alfabetizadoras da escola de tempo integral padre Josimo Morais Tavares (Palmas-TO): sobre as contribuições do PNAIC para suas práticas de ensino de Matemática. 204 f. Dissertação (Mestrado em Educação) - Universidade Federal Do Tocantins, Palmas, 2018. 
SILVA, Sirlene de Jesus dos Santos da. Desafios e contribuições do PNAIC Matemática para a prática pedagógica de professores da rede municipal de Curitiba. 111 f. Dissertação (Mestrado Profissional em Educação: Teoria e Prática de Ensino) - Universidade Federal do Paraná, Curitiba, 2016.

SIQUEIRA, Raissa Borges. A alfabetização matemática na perspectiva do letramento: relações entre a Matemática e a língua materna nos cadernos de formação do PNAIC. Dissertação (Mestrado em Educação) - Universidade de São Paulo, São Paulo, 2018.

SOUZA, Tamara M.de. Formação continuada com foco na alfabetização matemática: o impacto do PNAIC no Rio de Janeiro. 98 f. Dissertação (Mestrado em Ensino de Matemática) - Universidade Federal do Rio de Janeiro, Rio de Janeiro, 2016.

SOUZA, Renata Aparecida de. O Pacto Nacional pela Alfabetização na Idade Certa (PNAIC): formação e prática dos professores alfabetizadores no ensino da Matemática para alunos surdos. 199 f. Dissertação (Mestrado em Ensino de Ciências e Matemática) - Universidade do Estado de Mato Grosso, Barra do Bugres, 2018.

XAVIER, Rosa Seleta de Souza Ferreira; BARTHOLO, Tiago Lisboa. Os impactos do Pacto Nacional pela Alfabetização na Idade Certa: uma revisão sistemática. Educação em Revista, Belo Horizonte, v.35, 2019.

ZEICHNER, M. Kenneth. Para além da divisão entre professor-pesquisador e pesquisador acadêmico. In: GERALDI, Corinta Maria G., FIORENTINI, Dario; PEREIRA, Elisabete Monteiro de A. (org.). Cartografias do trabalho docente: professor(a) pesquisador(a). Campinas: Mercado das Letras/ALB, 2003.

ZEICHNER, M. Kenneth.; DINIZ-PEREIRA, J. E. A pesquisa dos educadores e a formação docente voltada para a transformação social. Cadernos de Pesquisa, v. 35 , n. 125 , p. $63-80,2005$.

WEBER, Daniela Guse. Pacto Nacional pela Alfabetização na Idade Certa: contribuições à prática pedagógica de professores que ensinam Matemática em classes de alfabetização. 230 fls. Dissertação (Mestrado em Educação Cientifica e Tecnológica) - Universidade Federal de Santa Catarina, Florianópolis, 2018. 


\section{Maria Iolanda Fontana}

Doutora em Educação pela Universidade Tuiuti do Paraná(UTP). Professora aposentada do Programa de Pós-Graduação em Educação da Universidade Tuiuti do Paraná(UTP), na linha de Práticas Pedagógicas: Elementos Articuladores. Membro do Núcleo de Pesquisa em Educação do Campo, Movimentos Sociais e Práticas Pedagógicas (NUPECAMP/UTP). E-mail: maria.iolanda.fontana@ gmail.com

\section{Ettiène Guérios}

Professora Titular na Universidade Federal do Paraná. Doutorado em Educação Matemática pela Universidade Estadual de Campinas (UNICAMP). Atua no Departamento de Teoria e Prática de Ensino, no Programa de Pós-Graduação em Educação (Acadêmico) e no Programa de Pós-Graduação em Educação: Teoria e Prática de Ensino (Profissional). Membro dos seguintes Grupos de Pesquisa certificados pelo CNPq: a) Cognição, Aprendizagem e Desenvolvimento Humano, b) Ensino e Aprendizagem de Ciências e Matemática e (c) Estudos e Pesquisas Pedagogia, Complexidade e Educação. E-mail: ettiene@ufpr.br

\section{Vanda Maria de Souza}

Licenciatura e bacharelado em Matemática, Mestre em Educação pela Universidade Tuiuti do Paraná (UTP). Professora de Matemática do Estado do Paraná e da Rede Municipal de Ensino de Curitiba (RME). Atua na RME, com formação continuada de professores dos anos iniciais. Desenvolve pesquisas, principalmente, sobre políticas e práticas de formação de professores. E-mail: vandam_sousa@yahoo.com.br 